\title{
Direct Power Control of Modular Multilevel Matrix Converter for Flexible AC Transmission System Applications
}

\author{
Alberto Duran, Matas Diaz, Efran Ibaceta, Felix Rojas and Pat Wheeler
}

\begin{abstract}
The Modular Multilevel Matrix Converter $\left(M^{3} C\right)$ has been proposed as an appropriate alternative for high-power machines due to characteristics such as modularity, mediumvoltage operation, high power quality and reliability. However, complex control systems are needed when its ports operate at equal frequencies, and the application of the $M^{3} C$ in equal frequencies applications, such as Flexible AC Transmission System (FACTS), can be restricted. Therefore, this paper presents a direct power control of an $M^{3} C$ for FACTS applications, including an enhanced control system to regulate the floating capacitor voltages, whereas the converter provides functions of FACTS. The effectiveness of the proposed control system is validated through simulations implemented in PLECS software.
\end{abstract}

Keywords-Modular Multilevel Converters, Modular Multilevel Matrix Converter, Flexible AC Transmission Systems.

\section{INTRODUCTION}

$\mathbf{F}$ LEXIBLE AC Transmission Systems (FACTS) are power electronics devices used to improve the electric power systems transmission lines dynamic and static behaviour [1]. The first FACT implemented was a Static Var Compensator (SVC). Due to their several advantages and applications, other topologies have been developed and implemented until today. Depending on the technology, FACTS allow to control different power system parameters, such as voltage control, active and reactive power flow control, transient stability, dynamic stability, damping control and short-circuit current limitation [2]. According to their grid connection, FACTS are classified as Series Control, Shunt Control and Combined Control[3].

Series Control FACTS implies a series voltage injection in the transmission line allowing reactive and active power compensation depending on the phase voltage, impedance line control and transmission line relief [4]. Parallel Control FACTS consider current injection in the connection point. If the injected current is in quadrature with the line voltage, it will create a Reactive Power Flow between the system and the FACTS device. This kind of control allows transmission line relief, power factor correction and voltage control [5].

Finally, Combined Control FACTS refers to Series-Series or Series-Parallel Controllers working together. These devices are controlled by an independent and coordinated system or a unified topology, namely, a physic connection between

A. Duran, M. Daz, E. Ibaceta and F. Rojas are with the Department of Electrical Engineering, the University of Santiago of Chile, Avenida Ecuador 3519 Santiago, Chile (e-mail: alberto.duran.s@usach.cl, matias.diazd@usach.cl, efrain.ibaceta@usach.cl, felix.rojas@usach.cl)

P. Wheeler is with the Faculty of Engineering, University of Nottingham, Nottingham, NG7 2RD, UK. (e-mail: pat.wheeler@nottingham.ac.uk)

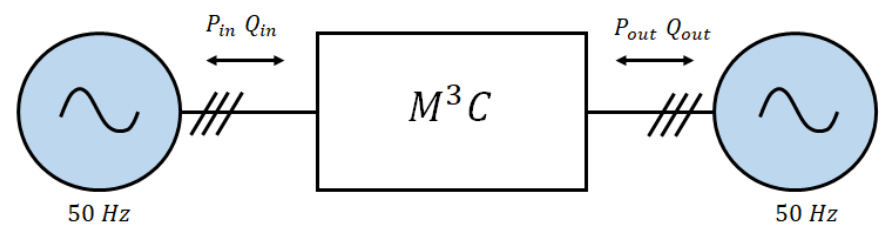

Fig. 1. $M^{3} C$ Topology for FACTS application

them. Usually, this connection is through a DC Link with a Voltage Source Converter (VSC) in Back-to-back topology [6].

A comparison between the most relevant FACTS devices and functions is presented in Table I. The compared devices are Static VAR Compensator (VAR), Series Static Synchronous Compensator (SSSC), Static Synchronous Compensator (STATCOM) and Unified Power Flow Controller (UPFC) [2].

FACTS devices are usually rated at high-power ratios. Therefore, the preferred technologies were based on thyritors. Despite of the high efficiency and high-power operation capability, power converters based on these technologies presents several drawbacks, such as low switching frequencies operation, not fully controllability and modularity, and large harmonic injection. Consequently, multilevel voltage source converters have emerged as a suitable alternatives for highpower applications. Most studied multilevel converters are the Neutral Point Clampled (NPC), the flying-capacitor and the Cascaded H-Bridge (CHB). Recently, the use of Modular Multilevel Cascaded Converters (MMCC) for FACTS applications has been validated in research and industrial projects due to its superior characteristics such as full modularity and easy extendibility to reach high voltage levels, redundancy, control flexibility and power quality [7], [8], [9]. MMCs are a novel power converter family, presented around 15 years ago [10]. The converters among this family are composed of power cells usually based on Half-Bridges or Full-Bridges. Among MMCs, the back to back Modular Multilevel Converter and the $M^{3} C$ are the most studied topologies for ACAC conversion [11]. The $M^{3} C$ is advantageously compared to other topologies for low-speed high-power applications because lower circulating currents are needed to mitigate the capacitor voltage oscillations [12].

Regarding FACTS applications, the B2B-M2C has been extensively used for High-Voltage Direct Current (HVDC) 
TABLE I

COMPARISON BETWEEN THE MOST RELEVANT FACTS DEVICES

\begin{tabular}{|c|c|c|c|c|c|c|}
\hline \multirow{2}{*}{$\begin{array}{r}2 * \text { FACTS } \\
\text { Device }\end{array}$} & \multicolumn{6}{|c|}{ Function } \\
\hline & $\begin{array}{l}\text { Voltage } \\
\text { Control }\end{array}$ & $\begin{array}{c}\text { Power } \\
\text { Flow } \\
\text { Control }\end{array}$ & $\begin{array}{l}\text { Reactive } \\
\text { Comp. }\end{array}$ & $\begin{array}{l}\text { Transient } \\
\text { Stability }\end{array}$ & $\begin{array}{l}\text { Dynamic } \\
\text { Stability }\end{array}$ & $\begin{array}{c}\text { Damping } \\
\text { Control }\end{array}$ \\
\hline SVC & $\mathbf{x}$ & & $\mathbf{x}$ & $\mathbf{x}$ & $\mathbf{x}$ & $\mathbf{x}$ \\
\hline SSSC & & $\begin{array}{l}\mathbf{x} \\
\end{array}$ & & $\mathbf{x}$ & $\mathbf{x}$ & \\
\hline $\begin{array}{l}\text { STAT } \\
\text { COM }\end{array}$ & $\mathbf{x}$ & & $\mathbf{x}$ & $\mathbf{x}$ & $\mathbf{x}$ & $\mathbf{x}$ \\
\hline UPFC & $\mathbf{x}$ & \begin{tabular}{|l|}
$x$ \\
\end{tabular} & $\mathbf{x}$ & \begin{tabular}{|l|}
$x$ \\
\end{tabular} & $\begin{array}{l}x \\
\end{array}$ & $\begin{array}{l}\mathbf{x} \\
\end{array}$ \\
\hline
\end{tabular}

transmission [13] [14]. Additionally, this type of converter has been studied as STATCOM [15] and UPFC [16]. Other MMCC topologies have also been studied in FACTS applications [17]. For example, the $M^{3} C$ have been proposed as a Unified Power Quality Conditioner (UPQC), being advantageously compared to other MMCC topologies [18].

The $M^{3} C$ control system had widely studied in [19], [20], [21], and as mentioned above, this converter has several advantages for low-speed applications. Nevertheless, the control of the $M^{3} C$ becomes complicated when both ports are operating at equal frequencies. Therefore, the control strategies are divided into Different-Frequency Mode (DFM) [19], [12], [22] and Equal-Frequencies Mode (EFM). EFM has been studied in [23], [24], [25], [26], [27]

In this context, this paper present a direct power control strategy for a $M^{3} C$ based FACTS, as shown in Fig. 1. The modelling and control of the $M^{3} C$ are described in section II and III. Vector control systems are used to regulate the floating capacitor voltages as proposed in [28], [29]. Finally, simulations results considering a $10 \mathrm{MW}$ model are included to validate the effectiveness of the proposed control strategies.

\section{AnAlysis of $M^{3} C$}

The $M^{3} C$ Topology is presented in Fig. 2, it is composed of nine clusters, each cluster comprises by $n$ cascaded power cells and an L-Filter. And the power cells are composed of a full-bridge circuit with a "floating" capacitor.

The recent studied uses linear transformation to analyse the $M^{3} C$, the Double $\alpha \beta 0$ Transform is used due to enable a decoupled representation of the $M^{3} C$ control systems [19]. Moreover, in [28] the $\Sigma \Delta$ Transformation is introduced to apply a Vector Control Strategy. The dynamic $M^{3} C$ model in Double $\alpha \beta 0-\Sigma \Delta$ are separated in the Voltage-Current Model (1), and the Power-Cluster Capacitor Voltage (CCV) Model detailed in (3) - (6).

\section{A. Voltage-Current Model of the $M^{3} C$}

This model is the result to apply the $\alpha \beta 0-\Sigma \Delta$ Transformation to the $a b c-r s t$ model Voltage Kirchhoff Law of the circuit presented in Fig. 2. The equations obtained is divided in four subsystems: $i_{\alpha 0}, i_{\beta 0}$ and the subscript $g$ represent the input port of the $M^{3} C$. The terms $i_{0 \alpha}, i_{0 \beta}$ and the subscript $m$ represent only the output port. Moreover, the circulating currents are represented by $i_{\alpha \alpha}^{\Sigma \Delta}, i_{\beta \alpha}^{\Sigma \Delta}, i_{\beta \alpha}^{\Sigma \Delta}$ and $i_{\beta \beta}^{\Sigma \Delta}$ and are

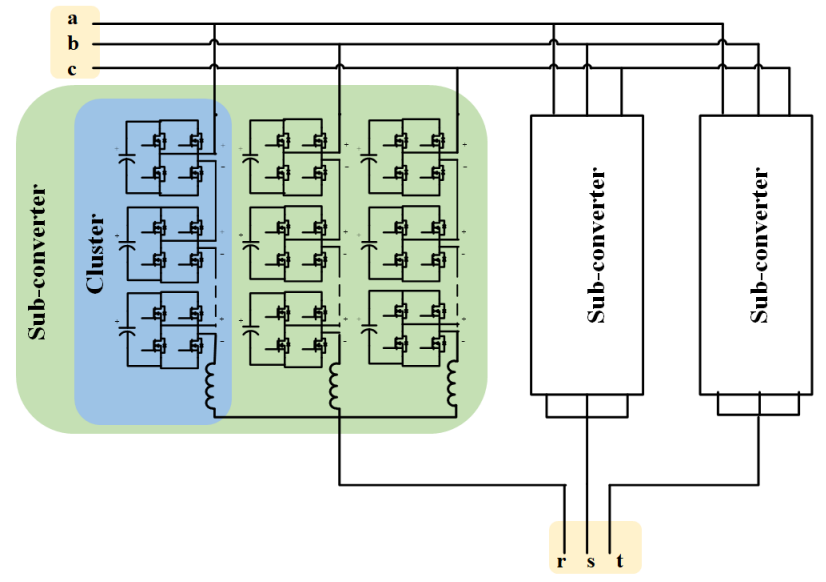

Fig. 2. $\quad M^{3} C$ Topology

totally independent to the others systems. Finally, $i_{00}$ and $v_{n}$ represent the common-mode circuit.

$$
\begin{gathered}
\sqrt{3}\left[\begin{array}{ccc}
0 & 0 & 0 \\
0 & 0 & 0 \\
v_{g_{\alpha}} & v_{g_{\beta}} & v_{g_{0}}
\end{array}\right]=L_{c} \frac{d}{d t}\left[\begin{array}{ccc}
i_{\alpha \alpha}^{\Sigma \Delta} & i_{\beta}^{\Sigma \Delta} & i_{0 \alpha} \\
i_{\alpha \beta}^{\Sigma \Delta} & i_{\beta \beta}^{\Sigma \Delta} & i_{0 \beta} \\
i_{\alpha 0} & i_{\beta 0} & i_{00}
\end{array}\right]+ \\
{\left[\begin{array}{ccc}
v_{\alpha \alpha}^{\Sigma \Delta} & v_{\beta \alpha}^{\Sigma \Delta} & v_{0 \alpha} \\
v_{\alpha \beta}^{\Sigma \Delta} & v_{\beta \beta}^{\Sigma \Delta} & v_{0 \beta} \\
v_{\alpha 0} & v_{\beta 0} & v_{00}
\end{array}\right]+\quad \sqrt{3}\left[\begin{array}{ccc}
0 & 0 & v_{m_{\alpha}} \\
0 & 0 & v_{m_{\beta}} \\
0 & 0 & v_{m_{0}}
\end{array}\right]+} \\
{\left[\begin{array}{ccc}
0 & 0 & 0 \\
0 & 0 & 0 \\
0 & 0 & 3 v_{n}
\end{array}\right]}
\end{gathered}
$$

Note that more details can be found in [30].

\section{B. Power-CCV Model of the $M^{3} C$}

The next model represents the Cluster Capacitor Voltage (CCV) dynamics. Due to the capacitors voltage are floating, in some operations points the converter produce large oscillations, the control system required is not straightforward. In this paper, the main operation point is when the input and output frequency ports are equal (EFM) and also when the reactive power flow in those ports is decoupled. The variations of the $\mathrm{CCV}$ with those conditions is presented in Fig. 3. The main oscillations are produced when $f_{\text {in }}=f_{\text {out }}$ and the power factor in the output port is near to zero.

The behaviour of the CCV is related to the clusters power, and assuming all power cells have the same capacitance and the internal losses in cluster inductor are dismissed, the CCV dynamics is given by (2).

$$
\frac{d}{d t} v_{c_{x y}} \approx \frac{P_{x y}}{C v_{c}^{*}}
$$

Where $x \in\{a, b, c\}, y \in\{r, s, t\}, P_{x y}=v_{x y} i_{x y}$, and all the capacitors are correctly regulated to $v_{c}^{*}$.

Applying the Double $\alpha \beta 0-\Sigma \Delta$ Transformation, the CCVs can be presented in function of the controllable terms as the Circulating currents and the common-mode voltage. Nevertheless, the CCV also have non-controllable terms which present the problems oscillations explained above. Therefore, the CCV 


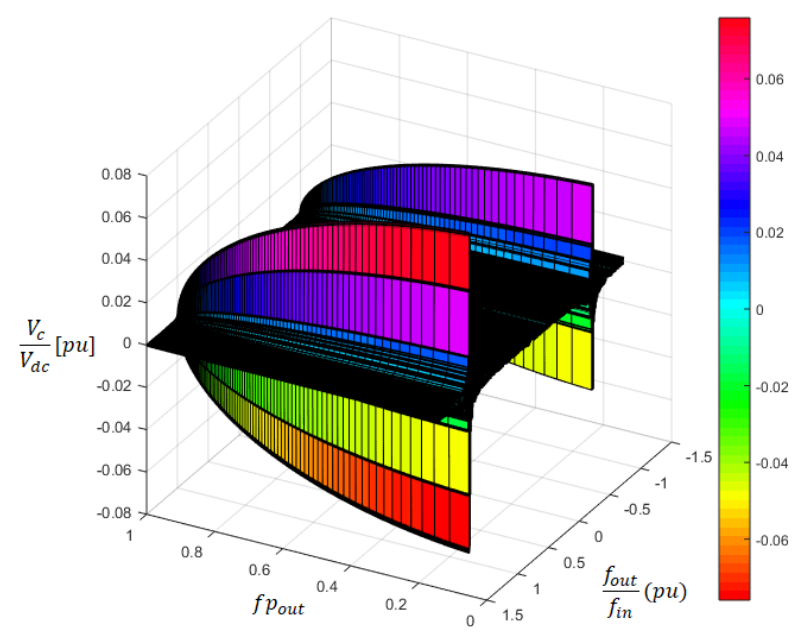

Fig. 3. CCV (pu) vs $f p_{\text {out }}$ vs $\frac{f_{\text {out }}}{f_{\text {in }}}(\mathrm{pu})$

terms are related with the frequencies ports in the next way: $v_{c_{1} \alpha \beta}^{\Sigma \Delta}$ has a frequency of $f_{m}-f_{g}, v_{c_{2} \alpha \beta}^{\Sigma \Delta}$ has a frequency of $f_{m}+f_{g}, v_{c_{0}}^{\alpha \beta}$ has a frequency of $2 f_{m}$, and $v_{c_{\alpha \beta}}^{0}$ has a frequency of $2 f g$. This four vector equations allow a simple analysis and implementation of Vector Control structures to regulate the floating capacitor voltages as proposed [28].

$$
\begin{gathered}
C v_{c}^{*} \frac{d v_{c_{1} \alpha \beta}^{\Sigma \Delta}}{d t} \approx \vec{P}_{1 \alpha \beta}^{\Sigma \Delta}=\frac{1}{6}\left(\vec{v}_{m_{\alpha \beta}}^{c} \overrightarrow{\mathrm{i}}_{g_{\alpha \beta}}-\vec{v}_{g_{\alpha \beta}} \overrightarrow{\mathrm{i}}_{m_{\alpha \beta}}^{c}\right)+ \\
\frac{1}{\sqrt{6}}\left(\vec{v}_{m_{\alpha \beta}} \overrightarrow{\mathrm{i}}_{2 \alpha \beta}^{\Sigma \Delta}-\vec{v}_{g_{\alpha \beta}}^{c} \overrightarrow{\mathrm{i}}_{2 \alpha \beta}^{\Sigma \Delta c}\right)-v_{n} \overrightarrow{\mathrm{i}}_{1 \alpha \beta}^{\Sigma \Delta} \\
C v_{c}^{*} \frac{d v_{c_{2} \alpha \beta}^{\Sigma \Delta}}{d t} \approx \vec{P}_{2 \alpha \beta}^{\Sigma \Delta}=\frac{1}{6}\left(\vec{v}_{m_{\alpha \beta}} \overrightarrow{\mathrm{i}}_{g_{\alpha \beta}}-\vec{v}_{g_{\alpha \beta}} \overrightarrow{\mathrm{i}}_{m \alpha \beta}\right)+ \\
\frac{1}{\sqrt{6}}\left(\vec{v}_{m_{\alpha \beta}}^{c} \overrightarrow{\mathrm{i}}_{1 \alpha \beta}^{\Sigma \Delta}-\vec{v}_{g_{\alpha \beta}}^{c} \overrightarrow{\mathrm{i}}_{1 \alpha \beta}^{\Sigma \Delta^{c}}\right)-v_{n} \overrightarrow{\mathrm{i}}_{2 \alpha \beta}^{\Sigma \Delta} \\
C v_{c}^{*} \frac{d v_{c_{0}}^{\alpha \beta}}{d t} \approx \vec{P}_{0}^{\alpha \beta}=\frac{1}{3 \sqrt{2}}\left(\vec{v}_{m_{\alpha \beta}}^{c} \overrightarrow{\mathrm{i}}_{m_{\alpha \beta}}^{c}\right)- \\
\frac{1}{\sqrt{3}}\left(\vec{v}_{g_{\alpha \beta}} \overrightarrow{\mathrm{i}}_{1 \alpha \beta}^{\Sigma \Delta^{c}}+\vec{v}_{g_{\alpha \beta}}^{c} \overrightarrow{\mathrm{i}}_{2 \alpha \beta}+v_{n} \overrightarrow{\mathrm{i}}_{m_{\alpha \beta}}\right) \\
C v_{c}^{*} \frac{d v_{c_{\alpha \beta}}^{0}}{d t} \approx \vec{P}_{\alpha \beta}^{0}=\frac{-1}{3 \sqrt{2}}\left(\vec{v}_{g_{\alpha \beta}}^{c} \overrightarrow{\mathrm{i}}_{g_{\alpha \beta}}^{c}\right)+ \\
\frac{1}{\sqrt{3}}\left(\vec{v}_{m_{\alpha \beta}} \overrightarrow{\mathrm{i}}_{1 \alpha \beta}^{\Sigma \Delta}+\vec{v}_{m_{\alpha \beta}}^{c} \overrightarrow{\mathrm{i}}_{2 \alpha \beta}-v_{n} \overrightarrow{\mathrm{i}}_{g_{\alpha \beta}}\right)
\end{gathered}
$$

\section{Direct Power Control System IN EQUAL FREQUENCY MODE}

A nested control system is proposed in this paper to allow decoupled reactive power control and active power transference between the ports of the $M^{3} C$ during EFM operation. The decoupled regulation of the converter is performed in Double $\alpha \beta 0-\Sigma \Delta$ frame, as presented in [28], enabling decoupled regulation the input-output ports variables and CCVs. The overview of the proposed control system is presented in Fig. 4.

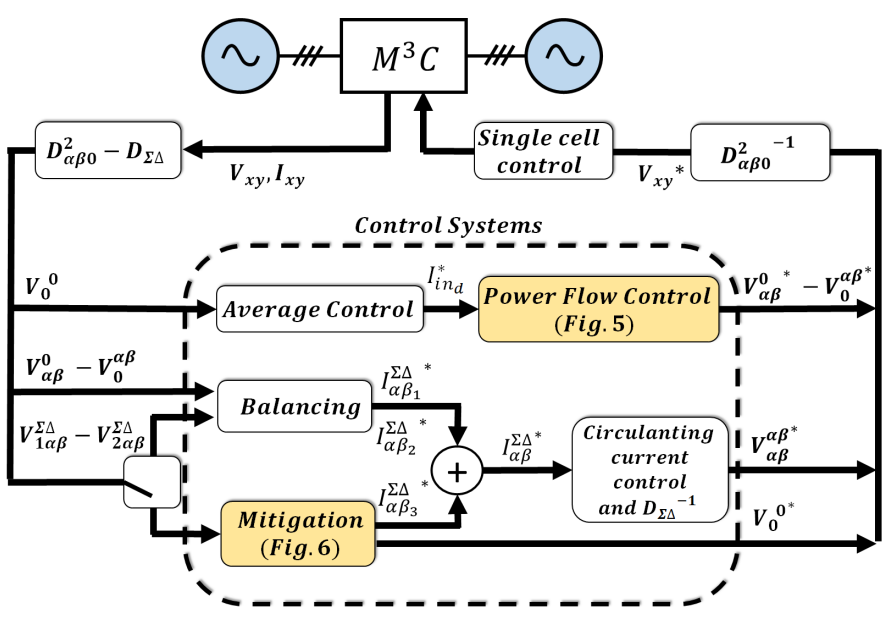

Fig. 4. Control system of $M^{3} C$ topology in EFM

\section{A. Input-output ports control}

The first step of the control system is the CCVs Average and the Power Flow Control. The CCVs Average Control is regulated by the component $V_{c_{00}}$ which depends on the direct input current $I_{g_{d}}$, controlling all the disturbances in the average capacitor voltage.

Then, the Power Flow control in converter ports is controlled by the direct and quadrature inputs and output currents, shown in Fig. 5.

The current references are given by reactive and active power references divided in the voltage ports. The output power reference divided in the direct output voltage give the direct output current references, and divided in the direct input voltage is the feed-forward current for the input port. For the quadrature frame, the reactive power references are different in output and input port and are divided in the output and input port voltage, respectively.

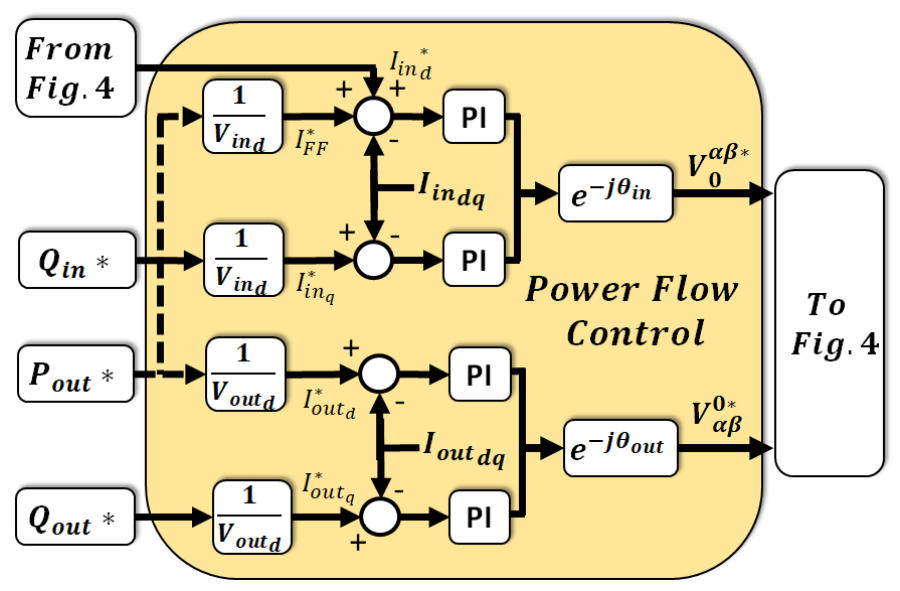

Fig. 5. Proposed power flow control

This control loop give the references for the ports components voltages $V_{c_{0}}^{\alpha \beta}$ and $V_{c_{\alpha \beta}}^{0}$.

\section{B. $M^{3} C$ control}

The average value of all the floating capacitor voltages is regulated using the component $v_{c_{00}}$. For the other voltage 
components in the, the control strategy applied depends on the operating mode. In DFM operation, it is assumed that the capacitor value is sufficient to attenuate the voltage oscillations produced at $\left(2 f_{g}, 2 f_{m}, f_{g} \pm f_{m}\right)$ and only the average values of the voltages in the have to be regulated to zero $u$

The first step of the control system is the regulation of all the floating capacitor voltages is regulated using the component $v_{c_{00}}$. This is performed controlling $V_{c_{00}}$, which depends on the direct input current $I_{g_{d}}$, controlling all the disturbances in the average capacitor voltage.

The CCV vectors in the , i.e. $v_{c_{1 \alpha \beta} \Delta}^{\Sigma \Delta}, v_{c_{2 \alpha \beta},}^{\Sigma \Delta}, v_{c_{0}}^{\alpha \beta}, v_{c_{\alpha \beta}}^{0}$ are regulated into two operational modes: Balancing and Mitigating control modes.

For balancing control, it is assumed that the capacitor value is sufficient to attenuate the capacitor voltage oscillations. Then, only the average values $\mathrm{CCV}$ vectors have to be regulated to zero using the circulating currents. This control regulates the $V_{c_{0}}^{\alpha \beta}, V_{c_{\alpha \beta}}^{0}, V_{c_{1 \alpha \beta} \Delta}^{\Sigma \Delta}$ and $V_{c_{2 \alpha \beta}}^{\Sigma \Delta}$, which need to be filtered at $2 w_{g}$ and $2 w_{m}, w_{m}-w_{g}$, and $w_{g}+w_{m}$, respectively.

For concerning to voltages $V_{c_{0}}^{\alpha \beta}$ and $V_{c_{\alpha \beta}}^{0}$ and currents $I_{c_{0}}^{\alpha \beta}$ and $I_{c_{\alpha \beta}}^{0}$ the name 'inter' is used. In the same way, the name 'intra' refers to voltages $V_{c_{1 \alpha \beta}}^{\Sigma \Delta}$ and $V_{c_{2 \alpha \beta}}^{\Sigma \Delta}$ and currents $I_{c_{1 \alpha \beta}}^{\Sigma \Delta}$ and $I_{c_{2 \alpha \beta}}^{\Sigma \Delta}$, as defined in [21], [31].

In mitigating control, as well as regulating the average values, the low frequency oscillations of frequency $f_{g} \pm f_{m}$ are regulated to zero injecting common-mode voltage. The transition from balancing and mitigating control system depends on the parameters of the converter such as cell capacitance, input/output port voltages and power factors. An analysis of the influence of these parameters is given in [32] and it is partially presented in Fig. 3. For this work, $f_{m}^{\max } \approx 0.9 f_{g}$ was used.

The mitigation control, shown in Fig. 6, regulates the circulating components using the common-mode voltage and the circulating currents as shown in (3) and (4), and is detailed described in [28]. Therefore, the mitigation control reduces the oscillations produced by the input and output power, represented by the first term of the right hand of 4 and 3, controlling the power term given by the common-mode voltage and circulating current. Nevertheless, a common-mode voltage is injected to the system. The magnitude and frequency of this voltage component are detailed studied in [33].

The output of the inter and mitigation control are the circulating currents required to operate the $M^{3} C$ in EFM, and those are controlled by next control step, the circulating current control,this control step give the $V_{\alpha \beta}^{\alpha \beta}$ reference, and the common-mode voltage reference $V_{0}^{0}$.

The voltage references are transform to $a b c$ frame, and the each voltage cluster are obtained $\left(V_{x y} \mathrm{x} \in\{a, b, c\}\right.$ and $\mathrm{y} \epsilon$ $\{r, s, t\})$. Finally, these voltages are controlled by the single cell control to obtain the voltage of each cell in the cluster.

\section{Simulation Results}

Simulation results of a $10 \mathrm{MW} M^{3} C$ have been obtained using PLECS software to validate the feasibility of the theoretical work proposed in this paper. The main parameters are provided in table II.

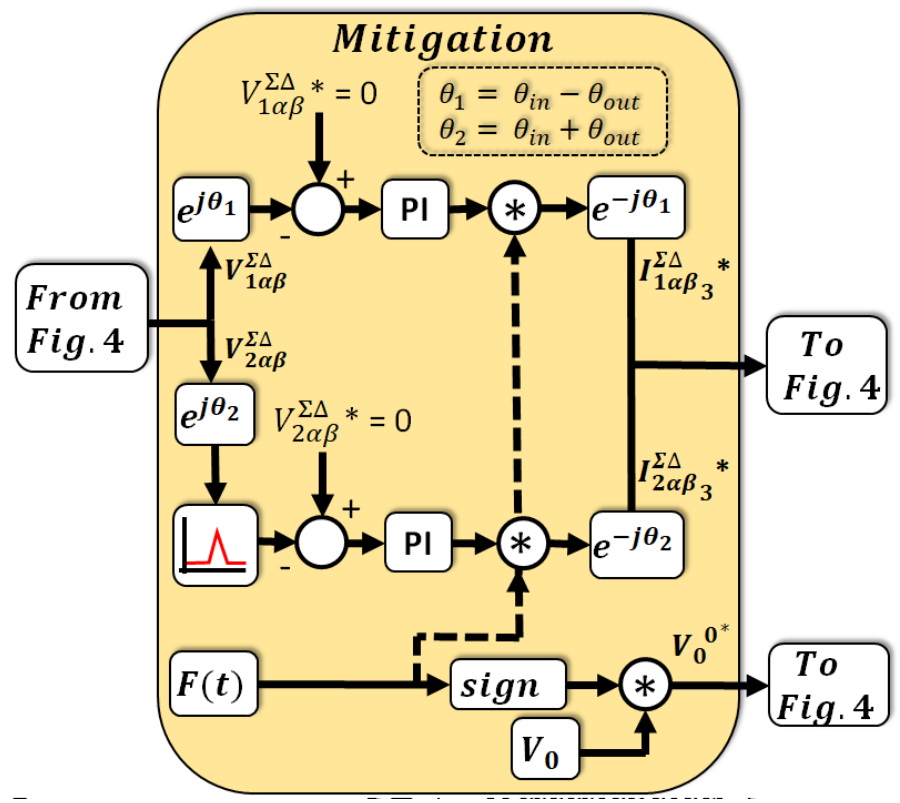

Fig. 6. Mitigation control

TABLE II

SiMUlation PARAMETERS

\begin{tabular}{|c|c|}
\hline Simulation Parameter & Value \\
\hline Nominal Power & $10 \mathrm{MW}$ \\
\hline Input Voltage / Frequency & $5.5 \mathrm{kV} / 50 \mathrm{~Hz}$ \\
\hline Output Voltage / Frequency & $5.39 \mathrm{kV} / 20-60 \mathrm{~Hz}$ \\
\hline Single cell C & $2200 \mathrm{uF}$ \\
\hline Capacitor Voltage & $13 \mathrm{kV}$ \\
\hline H [34] & $167 \mathrm{~ms}$ \\
\hline
\end{tabular}

The simulation results are presented in Fig. 7 and Fig. 8. For (b)-(d) the blue line represents the input variable and the red line the output variable.

In Fig.7, result considering three $10 \mathrm{~Hz}$ frequency steps from $20 \mathrm{~Hz}$ to $50 \mathrm{~Hz}$ in the output port, the mitigation control is available when the EFM is produced at second 3, before the system is working only with the balancing control.

The CCVs are correctly regulated for all operations points, as shown in Fig. 7 (a), even in the worst case when both ports are consuming reactive power and is working in EFM. The zoom over this area shows that voltage is properly regulated to the Average Value and have a small peak to peak voltage, and oscillations around $3-5 \%$ in the worst case.

The Active power in both ports is presented in Fig. 7 (c), the difference between them is produced due to the resistances included in the lines and clusters, causing more active power flow in the input port. The reactive Power Flow is decoupled, as shown in Fig. 7 (d), the systems are allowed to operate with different power factors in their ports.

The circulating currents are presented in Fig. 7 (e) to $(\mathrm{g})$. The balancing currents of the inter and intra control are shown in Fig. 7 (e) and Fig. 8 (f). In the second 3, the intra current change to a mitigation current presented in Fig. 7 (g) when the output frequency change to $50 \mathrm{~Hz}$.

In Fig. 8, results considering a change to $60 \mathrm{~Hz}$ in the output port are presented. In this case the mitigation control change 


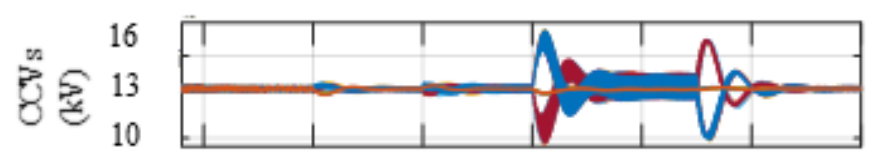

(a)
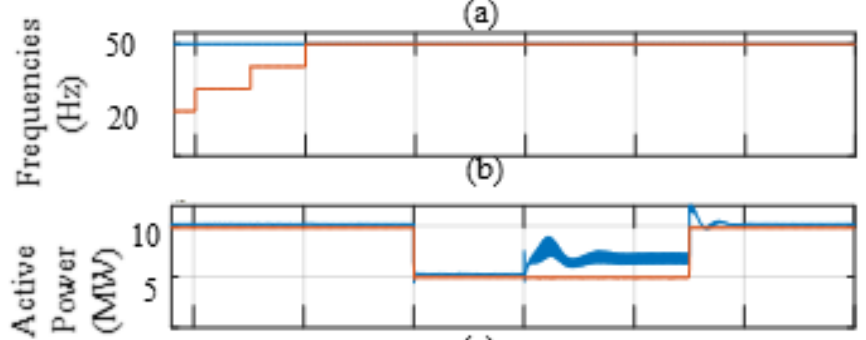

(c)

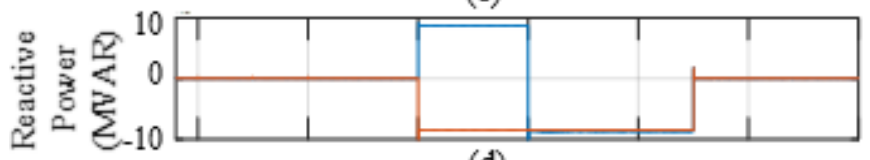

(d)
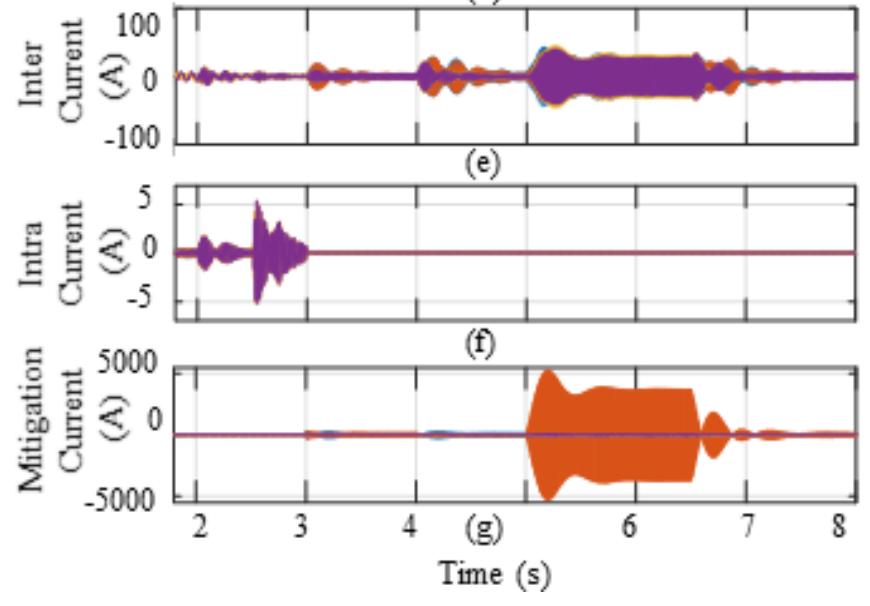

Fig. 7. (a) $\mathrm{CCV}$ in different frequencies and power flow conditions (b) In and Out frequencies (c) In and Out Active power flow (d) In and Out Reactive power flow.(e) Balancing currents of the inter control (f) Balancing currents of the intra control (e) Mitigation currents.

to balancing control because the converter operates in DFM and just the average value of the $\mathrm{CCV}$ is regulated using the circulating currents.

Fig. 8 (a) shows adequate regulation of the CCVs for the whole operational range. It is noticeable that the CCV oscillations are always bounded into a $10-15 \%$ band. In Fig. 8 (b) the input and output frequency are presented.

The active and reactive power flow are shown in Fig. 8 (c) and Fig. 8 (d) respectively. In the same way as the previous case, the circulating currents are presented in Fig. 8 (e) to (g), in this case the mitigation current changes to the intra current, shown in Fig. 8 (f) and Fig. 8 (g), when the output frequency change from $50 \mathrm{~Hz}$ to $60 \mathrm{~Hz}$.

\section{CONCLUSION}

A direct power control strategy for a $M^{3} C$ based FACTS is presented in this paper. The modelling of the system is presented and analysed in Double $\alpha \beta 0$ frame, allowing the implementation of nested vector control schemes. Simulation results are presented to validate the effectiveness of the proposed direct power control of the $M^{3} C$ operating in EFM

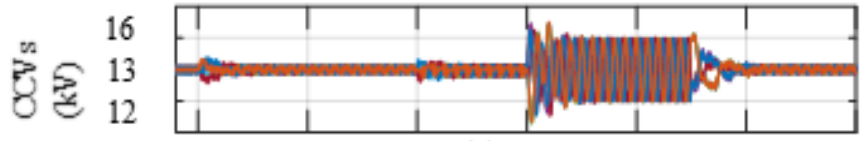

(a)

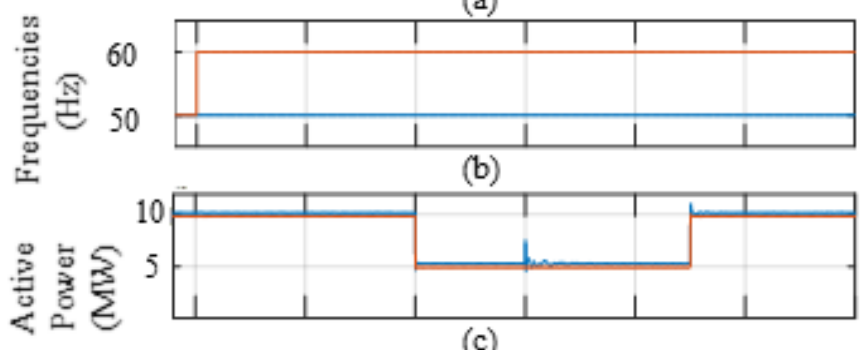

(c)
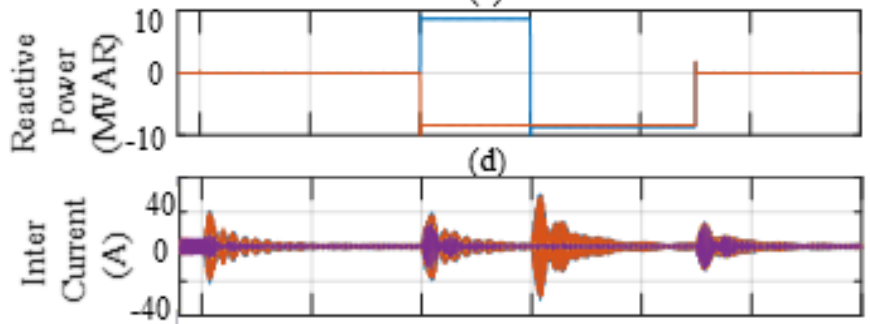

(e)
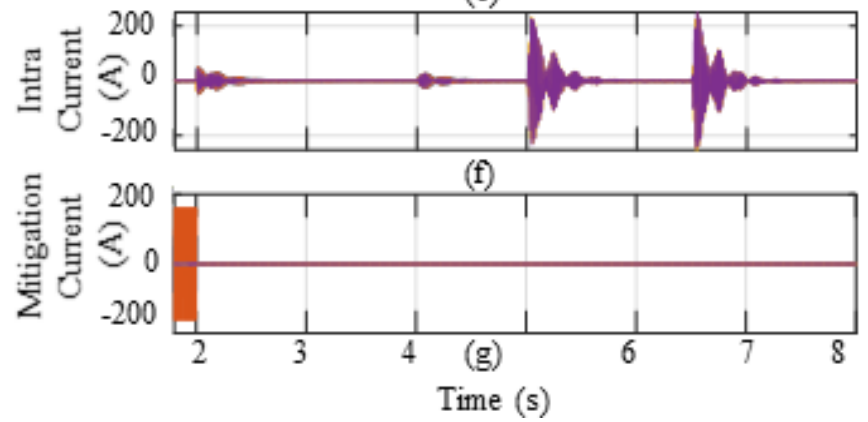

Fig. 8. (a) $\mathrm{CCV}$ in different frequencies and power flow conditions (b) In and Out frequencies (c) In and Out Active power flow (d) In and Out Reactive power flow.(e) Balancing currents of the inter control (f) Balancing currents of the intra control (e) Mitigation currents.

and LFM, allowing active power flow and totally decoupled reactive power transference among the converter ports, even for EFM operation.

\section{ACKNOWLEDGMENT}

The funding provided by the postgraduate program of the University of Santiago of Chile is acknowledged. The support provided by project DICYT-USACH 091813DD is also recognised.

\section{REFERENCES}

[1] N. Acharya, A. Sode-Yome, and N. Mithulananthan, "Facts about flexible AC transmission systems (FACTS) controllers: practical installations and benefits," Australian Universities Power Engineering Conference (AUPEC), AUPEC-2005, no. September, pp. 1 - 7, 2005.

[2] F. M. Albatsh, S. Mekhilef, S. Ahmad, H. Mokhlis, and M. A. Hassan, "Enhancing power transfer capability through flexible AC transmission system devices: a review," Frontiers of Information Technology \& Electronic Engineering, vol. 16, no. 8, pp. 658-678, 2015.

[3] L. G. Narain G. Hingorani, Understanding FACTS: Concepts and technology of flexible ac transmission systems, 1383.

[4] K. K. Sen, "SSSC - Static Synchronous Series Compensator: Theory, modeling, and applications," IEEE Transactions on Power Delivery, vol. 13, no. 1, pp. 241-246, 1998. 
[5] X. P. Zhang, E. Handschin, and M. Yao, "Multi-control functional static synchronous compensator (STATCOM) in power system steady-state operations," Electric Power Systems Research, vol. 72, no. 3, pp. 269 $278,2004$.

[6] K. K. Sen and E. J. Stacey, "UPFC - Unified Power Flow Controller: Theory, modeling, and applications," IEEE Transactions on Power Delivery, vol. 13, no. 4, pp. 1453-1460, 1998.

[7] S. Kouro, J. Rodriguez, B. Wu, S. Bernet, and M. Perez, "Powering the future of industry: High-power adjustable speed drive topologies," IEEE Industry Applications Magazine, vol. 18, no. 4, pp. 26-39, 2012.

[8] M. M. S. Kouro, K. Gopakumar, J. Pou, L. G. Franquelo, B. Wu, J. Rodriguez, M. A. Pérez, and J. I. Leon, "Recent advances and industrial applications of multilevel converters," IEEE Transactions on Industrial Electronics, vol. 57, no. 8, pp. 2553-2580, 2010.

[9] H. Akagi, "Classification, terminology, and application of the modular multilevel cascade converter (MMCC)," IEEE Transactions on Power Electronics, vol. 26, no. 11, pp. 3119-3130, 2011.

[10] A. Lesnicar and R. Marquardt, "A new modular voltage source inverter topology," Proceedings of the 10th European Conference on Power Electronics and Applications.Toulouse,France:IEEE, pp. 1-10, 2003.

[11] Y. Okazaki, W. Kawamura, M. Hagiwara, H. Akagi, T. Ishida, M. Tsukakoshi, and R. Nakamura, "Experimental Comparisons Between Modular Multilevel DSCC Inverters and TSBC Converters for Medium-Voltage Motor Drives," IEEE Transactions on Power Electronics, vol. 32, no. 3, pp. 1802-1817, mar 2017. [Online]. Available: http://ieeexplore.ieee.org/document/7464367/

[12] W. Kawamura and H. Akagi, "Control of the modular multilevel cascade converter based on triple-star bridge-cells (MMCC-TSBC) for motor drives," 2012 IEEE Energy Conversion Congress and Exposition, ECCE 2012, pp. 3506-3513, 2012.

[13] R. Marquardt, "Modular Multilevel Converter: An universal concept for HVDC-Networks and extended DC-bus-applications," 2010 International Power Electronics Conference - ECCE Asia -, IPEC 2010, pp. 502-507, 2010.

[14] S. Allebrod, R. Hamerski, and R. Marquardt, "New transformerless, scalable modular multilevel converters for HVDC-transmission," PESC Record - IEEE Annual Power Electronics Specialists Conference, pp. 174-179, 2008.

[15] I. Sanz, M. Moranchel, E. J. Bueno, and F. J. Rodriguez, "Analysis of medium voltage modular multilevel converters for FACTS applications," IECON Proceedings (Industrial Electronics Conference), pp. 64596464, 2016.

[16] G. Zhuo, D. Jiang, and X. Lian, "Modular multilevel converter for unified power flow controller application," Proceedings - 2012 3rd International Conference on Digital Manufacturing and Automation, ICDMA 2012, vol. 2, pp. 545-549, 2012.

[17] M. Pereira, D. Retzmann, J. Lottes, M. Wiesinger, and G. Wong, "SVC PLUS: An MMC STATCOM for network and grid access applications," 2011 IEEE PES Trondheim PowerTech: The Power of Technology for a Sustainable Society, POWERTECH 2011, pp. 1-5, 2011.

[18] Q. Xu, F. Ma, A. Luo, Z. He, and H. Xiao, "Analysis and Control of M3C-Based UPQC for Power Quality Improvement in Medium/HighVoltage Power Grid," IEEE Transactions on Power Electronics, vol. 31, no. 12, pp. 8182-8194, 2016.

[19] W. Kawamura, M. Hagiwara, and H. Akagi, "Experimental verification of a modular multilevel cascade converter based on triple-star bridgecells (MMCC-TSBC) for motor drives," vol. 50, no. 5, pp. 454-459, 2014.

[20] F. Kammerer, M. Gommeringer, J. Kolb, and M. Braun, "Energy balancing of the Modular Multilevel Matrix Converter based on a new transformed arm power analysis," 2014 16th European Conference on Power Electronics and Applications, EPE-ECCE Europe 2014, 2014.

[21] M. Diaz, R. Cardenas, M. Espinoza, F. Rojas, A. Mora, J. C. Clare, and P. Wheeler, "Control of wind energy conversion systems based on the modular multilevel matrix converter," IEEE Transactions on Industrial Electronics, vol. 64, no. 11, pp. 8799-8810, Nov 2017.

[22] F. Kammerer, J. Kolb, and M. Braun, "Fully decoupled current control and energy balancing of the Modular Multilevel Matrix Converter," in 2012 15th International Power Electronics and Motion Control Conference (EPE/PEMC). IEEE, sep 2012, pp. LS2a.3-1-LS2a.3-8. [Online]. Available: http://ieeexplore.ieee.org/lpdocs/epic03/wrapper.htm?arnumber=6397408

[23] B. Fan, K. Wang, P. Wheeler, C. Gu, and Y. Li, "An Optimal Full Frequency Control Strategy for the Modular Multilevel Matrix Converter Based on Predictive Control," IEEE Transactions on Power Electronics, vol. 33, no. 8, pp. 6608-6621, 2018.
[24] W. Kawamura, Y. Chiba, M. Hagiwara, and H. Akagi, "Experimental Verification of an Electrical Drive Fed by a Modular Multilevel TSBC Converter When the Motor Frequency Gets Closer or Equal to the Supply Frequency," IEEE Transactions on Industry Applications, vol. 53, no. 3, pp. 2297-2306, 2017.

[25] W. Kawamura, M. Hagiwara, and H. Akagi, "Control and experiment of a modular multilevel cascade converter based on triple-star bridge cells," IEEE Transactions on Industry Applications, vol. 50, no. 5, pp. 3536-3548, 2014.

[26] W. Kawamura, Y. Chiba, M. Hagiwara, and H. Akagi, "Experimental Verification of an Electrical Drive Fed by a Modular Multilevel TSBC Converter When the Motor Frequency Gets Closer or Equal to the Supply Frequency," IEEE Transactions on Industry Applications, vol. 53, no. 3, pp. 2297-2306, 2017.

[27] W. Kawamura, Y. Chiba, and H. Akagi, "A Broad Range of Speed Control of a Permanent Magnet Synchronous Motor Driven by a Modular Multilevel TSBC Converter," IEEE Transactions on Industry Applications, vol. 53, no. 4, pp. 3821-3830, 2017.

[28] M. Diaz, R. Cardenas, M. Espinoza, C. M. Hackl, F. Rojas, J. C. Clare, and P. Wheeler, "Vector control of a modular multilevel matrix converter operating over the full output-frequency range," IEEE Transactions on Industrial Electronics, vol. 66, no. 7, pp. 5102-5114, 2019.

[29] M. Diaz, M. Espinosa, F. Rojas, P. Wheeler, and R. Cardenas, "Vector control strategies to enable equal frequency operation of the modular multilevel matrix converter," The Journal of Engineering, vol. 2019, no. 17, pp. 4214-4219, 2019

[30] W. Kawamura, M. Hagiwara, and H. Akagi, "Control and experiment of a modular multilevel cascade converter based on triple-star bridge cells," IEEE Transactions on Industry Applications, vol. 50, no. 5, pp. 3536-3548, 2014

[31] M. Diaz, F. Rojas, M. Espinoza, A. Mora, P. Wheeler, and R. Cardenas, "Closed loop vector control of the modular multilevel matrix converter for equal input-output operating frequencies," in Proceedings - 2017 IEEE Southern Power Electronics Conference, SPEC 2017, vol. 2018Janua, no. October. IEEE, dec 2018, pp. 1-6. [Online]. Available: $\mathrm{http} / / /$ ieeexplore.ieee.org/document/8333629/

[32] J. Kucka, D. Karwatzki, and A. Mertens, "AC/AC modular multilevel converters in wind energy applications: Design considerations," in 2016 18th European Conference on Power Electronics and Applications, EPE 2016 ECCE Europe. IEEE, sep 2016, pp. 1-10. [Online]. Available: http://ieeexplore.ieee.org/document/7695542/

[33] M. Espinoza, E. Espina, M. Diaz, A. Mora, and R. Cardenas, "Improved control strategy of the modular multilevel converter for high power drive applications in low frequency operation," 2016 18th European Conference on Power Electronics and Applications, EPE 2016 ECCE Europe, 2016.

[34] H. Fujita, Y. Watanabe, and H. Akagi, "Control and analysis of a unified power flow controller," PESC Record - IEEE Annual Power Electronics Specialists Conference, vol. 1, pp. 805-811, 1998. 